\title{
Influence of the Home Cooking Practices on the Bioactive Components of Two Important Edible Herbs- Amaranthus viridis and Amaranthus tricolor
}

\author{
Debleena Roy ${ }^{1}$, Renia Mullick', Namrata Chakraborty ${ }^{1}$, Jayeesha Ghosh ${ }^{1}$, Debapriya Das', Bidisha Mallick ${ }^{1}$ Dipu Samanta ${ }^{2, *}$ \\ 'Department of Botany, Lady Brabourne College, Surahwardy Avenue, Kolkata, West Bengal, INDIA. \\ ${ }^{2}$ Department of Botany, Dr. Kanailal Bhattacharyya College, Ramrajatala, Howrah, West Bengal, INDIA.
}

\begin{abstract}
Background: Antioxidants are substances that delays or inhibits the oxidation of a substrate by countering highly unstable entities (ROS and free radicals) that can cause cellular damage. Some natural source of antioxidants is green leafy vegetables like Amaranthus. Results of vegetable composition are usually determined on raw material, however for nutritional purposes most of them are cooked in different ways before consumption. In India, vegetables we consume are cooked by boiling in water, fried in oil or microwaved. Objectives: This paper mainly focuses on the comparative study of raw, boiled and fried forms of Amaranthus viridis and Amaranthus tricolor to ensure which form of vegetable intake provides proper amount of antioxidants to our body in order to boost the antioxidant profile. Methods: Total phenol content, flavonoid content, free radical scavenging activity, estimation of total inhibitor capability and estimation of Quercetin, Kaempferol and Rutin by HPTLC analysis were carried on raw, boiled and fried forms of Amaranthus viridis and Amaranthus tricolor. Results: The cooking processes lead significant changes in physical
\end{abstract}

characteristics and chemical composition influencing the concentration and bioavailability of bioactive compounds of vegetables. The fried material is heated only on the surface so that the phenolic antioxidant losses are insignificant. Conclusion: The raw forms of green and fried form of red are more suitable for uptake. Also, green species contains more antioxidants than the red one.

Key words: Amaranthus, Antioxidant, Flavonoids, Phenolics, HPTLC.

Correspondence

Dr. Dipu Samanta

Department of Botany, Dr. Kanailal Bhattacharyya College, Ramrajatala, Howrah-711104, West Bengal, INDIA.

Phone: +919804959921

Email: dipusamanta2010@gmail.com

DOI: 10.5530/ijpi.2021.1.6

\section{INTRODUCTION}

A healthy diet and lifestyle measure cornerstones of good health and reduces risk for disease. A healthy lifestyle includes diet supported, selection and moderation coupled with regular physical activity commensurate with one's age, gender and body constitution. Micronutrient Deficiencies (MNDs) are major concerns of public health and of socioeconomic importance worldwide having an effect on lowincome countries. However health issues in industrialized societies, also, impacts the population. ${ }^{1}$ By overwhelming a healthy diet, several of the health issues are avoided. Among the various plant-based food sources, leafy vegetables provide antioxidants, minerals and vitamins. It has been established that increase in vegetable consumption reduces the chance of cancer, cardiovascular diseases and mortality as a result of the presence of antioxidants like water-soluble Vitamin, Vitamin E, carotenoids and polyphenols.

Amaranthus (family Amaranthaceae), commonly called amaranths, are herbaceous plant that is either annual or perennial. Some amaranth species square measure cultivated as leaf vegetables. Most of the Amaranthus species are summer annual weeds, commonly known as pigweeds. The genus Amaranthus varies in flower, leaf and stem colour with a variety of pigments from the spectrum of maroon to crimson and may grow lengthwise from 3-8 foot (0.9-2.4 m) tall with a cylindrical, succulent, fibrous stem. The genus, is native to North America.

Amaranth leaves are called super food as they are beneficial for our health. Amaranth leaves contain essential phytonutrients and antioxidants that facilitate to reduce inflammation within the body and supply an additional boost of nutrition to one's health. ${ }^{2}$ The plant is a rich source of protein, low in calories, high in fiber and different minerals. The plant contains flavonoid, polyphenolic antioxidants like carotenoid, zeaxanthin and xanthophyll which offer a protecting layer against stress caused by free radicals. ${ }^{3,4}$ Amongst all the inexperienced leafed vegetables, across the board, amaranth leaves have the very best amount of naphthoquinone, Vitamin B and different minerals. Having a protein-rich diet results in suppression of hunger as they scale back hypoglycemic agent levels within the blood and keep one feeling surfeited.

Amaranthus tricolor L. (laalshaak) has antitumor, anti-inflammatory properties as they contain minerals like iron and calcium, pigments like betalains and flavonoids. Inexperienced amaranth (Amaranthus viridis L.) (noteyshaak), on the other hand is historically accustomed cure of constipation, eczema, anemia, bronchitis, eye infections, infectious disease etc. ${ }^{5}$ In India, Amaranthus leaves are used in different ways, either by cooking the Amaranth leaves with many spices, garlic and onion, called lalsaak or chaulaisaak. Sometimes, it's conjointly hard-baked with lentils and served with rice or roti. Another variation is finished wherever a form of curry is formed with Amaranth leaves and gram flour. In Kerala, a dish referred to as cheerathoranis created by finely chopping the amaranth leaves and cooking them with grated coconut, chilies, curry leaves and bound spices. In state, it's called keeraimasial and served with steamed rice. Fresh, tender leaves and shoots of Amaranth is devoured raw in salads or as juice.

Several studies to date have largely been conducted either in raw kind or blanched kinds of the plant sample. However, no reports to date 
document the comparative analysis of the inhibitory activity in raw and cooked forms. Different investigation provides a vital documentation on discovery and quantification the antioxidants present in 2 species of amaranths- $A$. viridis and genus A. tricolor was performed. A comparative analysis of the inhibitor activity in raw and cooked forms between the 2 samples to know the optimum change of state conditions which will enhance the diet uptake level of antioxidants in these samples.

\section{MATERIALS AND METHODS}

\section{Materials}

Fresh samples of Amaranthus viridis and Amaranthus tricolor were obtained from local markets (Figure 1a and 1b) followed by authentic identification from University of Calcutta. The vegetables were checked for dirt or visible damages, which were discarded. The samples were utilized for extraction, fresh, without preservation.

\section{Method}

\section{Preparation of material}

a) Raw: For the preparation of raw plant extract, leaves of Amaranthus viridis and Amaranthus tricolor were washed and measured (2 gm). Plant extract was made in $50 \mathrm{ml}$ of $80 \%$ methanol.

b) Boiled: Leaves of $A$. viridis and A. tricolor were washed and measured ( $2 \mathrm{gm}$ ). The leaves were then boiled in water for 5-6 min till the leaves became soft. After boiling, excess water was removed with the help of blotting paper and plant extract was made in $50 \mathrm{ml}$ of $80 \%$ methanol.

c) Fried: Leaves of $A$. viridis and A. tricolor were washed and measured $(2 \mathrm{gm})$. The leaves were then fried in mustard oil and the excess oil was removed with the help of blotting paper and the plant extract was made in $50 \mathrm{ml}$ of $80 \%$ methanol. The abbreviations of different samples is mentioned in Table 1.

\section{Estimation of phenolics}

The amount of total phenolics in extracts was estimated with the FolinCiocalteau reagent. Gallic Acid was used as a standard and the total phenolics were expressed as $\mathrm{mg} / \mathrm{ml}$ gallic acid equivalence (GAE). 0.25 $\mathrm{mg} / \mathrm{ml}$ of plant extract were prepared in methanol and $0.5 \mathrm{ml}$ of every sample in raw, deep-fried and boiled form was introduced into the tube. It was then mixed with $2.5 \mathrm{ml}$ of tenfold dilute Folin-Ciocalteau reagent and a $2 \mathrm{ml}$ of $7.5 \%$ of washing soda. The reaction mixture was allowed to face for thirty minutes at room temperature and also the absorbance was measured at $765 \mathrm{~nm}$ in UV-Vis spectrophotometer. ${ }^{6}$ The concentration was calculated using gallic acid as the standard and the results were expressed as $\mathrm{mg}$ gallic acid equivalence ( $\mathrm{mg} / \mathrm{ml} \mathrm{GAE}$ ).
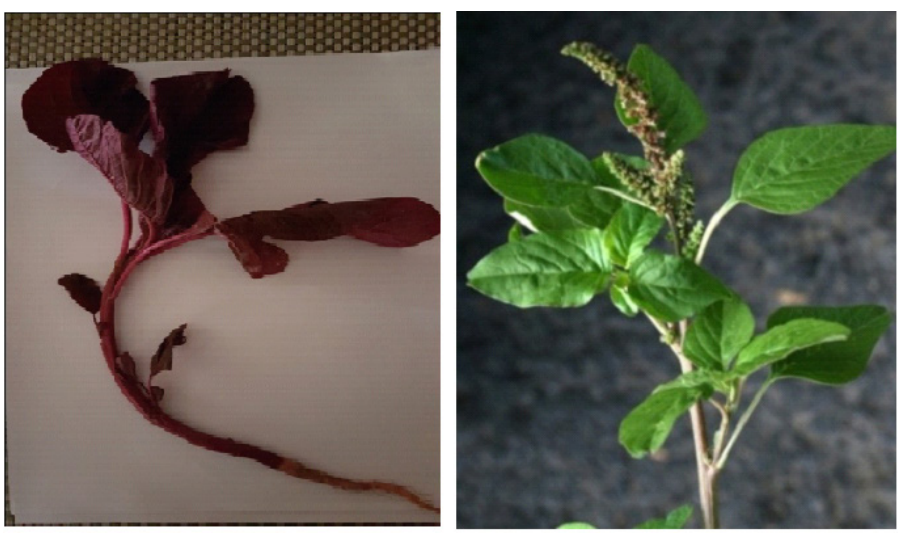

Figure 1: (a) Amaranthus viridis (b) Amaranthus tricolor.

\section{Estimation of total flavonoid}

Total flavonoid content was measured by the aluminum chloride colorimetric assay. In this method Quercetin was used as standard and flavonoid contents were measured as Quercetin equivalent from the standard curve in $\mathrm{mg} / \mathrm{ml}$ QE. $1 \mathrm{ml}$ extract $(1 \mathrm{mg} / \mathrm{ml})$ of concentration $10 \mathrm{mg} / \mathrm{ml}$ was added separately to a $10 \mathrm{ml}$ volumetric flask containing 4 $\mathrm{ml}$ of distilled water. $0.3 \mathrm{ml} 5 \% \mathrm{NaNO}_{2}$ was added. After $5 \mathrm{~min}, 0.3 \mathrm{ml}$ $10 \% \mathrm{AlCl}_{3}$ was added. ${ }^{6}$ The solution was mixed well and the absorbance was measured against prepared reagent blank at $510 \mathrm{~nm}$ by UV-Vis spectrophotometer.

\section{Estimation of total inhibitor capability (TAC)}

Plant extracts were dissolved in methanol to obtain a concentration of $3 \mathrm{mg} / \mathrm{ml}$. $0.3 \mathrm{ml}$ of extract was placed in a test tube; $3 \mathrm{ml}$ of reagent solution $\left(0.6 \mathrm{M} \mathrm{H}_{2} \mathrm{SO}_{4}+28 \mathrm{mM}\right.$ Sodium phosphate $+4 \mathrm{mM}$ Ammonium Molybdate) was supplemented. The reaction mixture was incubated at $95^{\circ} \mathrm{C}$ for $90 \mathrm{~min}$. The mixture was cooled to room temperature; the absorbance was measured by using Systronics UVVis spectrophotometer at $695 \mathrm{~nm}$ against blank. The experiment was performed in triplicate. A calibration curve was constructed, using ascorbic acid $(100-500 \mu \mathrm{g} / \mathrm{ml})$ as standard and total antioxidant activity of extract expressed as ascorbic acid equivalents ( $\mathrm{mg} / \mathrm{ml} \mathrm{Asc} \mathrm{E).?}$

\section{Free radical scavenging activity}

The antioxidant activity of the extracts was assessed by their ability to scavenge 2-2-diphenyl-1-picrylhydrazyl stable radicals (DPPH). The DPPH is a stable free radical, which has been accepted as a tool for estimating free radical scavenging activity of the natural extracts. ${ }^{8,9}$ To evaluate the antioxidative activity of specific compounds or extracts, the latter was allowed to react with a stable radical DPPH in a methanol solution. $1 \mathrm{ml}$ of methanolic extract and $5 \mathrm{ml}$ of freshly prepared 0.1 $\mathrm{mM}$ DPPH methanolic solution were thoroughly mixed and kept in the dark for $60 \mathrm{~min} .{ }^{89}$ The absorbance of the reaction mixture at 517 $\mathrm{nm}$ was measured by spectrophotometer. The blank set was prepared by replacing the extract with $1 \mathrm{ml}$ methanol. The percentage of free radical scavenging activity was calculated as follows:

Free radical scavenging $(\%)=100-\left(1-\mathrm{A}_{\text {sample }} / \mathrm{A}_{\text {blank }}\right)$

Where,

$A_{\text {blank }}$ is the absorbance of the control and $A_{\text {sample }}$ is the absorbance of the extract or in this case ascorbic acid.

\section{Estimation of Quercetin, Kaempferol and Rutin by HPTLC analysis}

The $100 \mathrm{mg}$ of ethanolic extract of plant material was dissolved in $1 \mathrm{~mL}$ ethanol and centrifuged at $971 \mathrm{~g}$ for $5 \mathrm{~min}$. A $2 \mu \mathrm{L}$ aliquot of the above test solution and $2 \mu \mathrm{L}$ of a standard solution were loaded as $5 \mathrm{~mm}$ band length in a $3 \times 10$ silica gel $60 \mathrm{~F}_{254}$ TLC plate. The samples-loaded plate

Table 1: Different samples used experiment.

\begin{tabular}{cc}
\hline Sample Name & Sample Description \\
\hline AG1 & Green Amaranthus Raw \\
AG2 & Green Amaranthus Boiled \\
AG3 & Green Amaranthus Fried \\
AR1 & Red Amaranthus Raw \\
AR2 & Red Amaranthus Boiled \\
AR3 & Red Amaranthus Fried \\
\hline
\end{tabular}


was kept in TLC twin trough developing chamber with respective mobile phases and the plate was developed in the respective mobile phase. The developed plate was dried by hot air to evaporate solvents from the plate. The plate was kept in a photo-documentation chamber and the images were captured in white light and at $254 \mathrm{~nm}$ and $366 \mathrm{~nm}$. The developed plate was sprayed with respective spray reagent and dried at $100^{\circ} \mathrm{C}$ in a hot air oven. The plate was documented in daylight and at UV $366 \mathrm{~nm}$ mode using the photo-documentation chamber. ${ }^{10}$ After derivatization, the plate was fixed and scanning was done at $500 \mathrm{~nm}$ by TLC Scanner. The peak table, peak display and peak densitogram were recorded.

\section{Statistical analysis}

All the data obtained were analyzed statistically using $\mathrm{R}$ programming language. One way ANOVA was done to test significant difference between the treatments. Tukey's test was done for pairwise testing. Kruskal Wallis test was done to test the effect of treatment. Dunn test for pairwise comparison was done where applicable.

\section{RESULTS}

\section{Estimation of Phenolics, Flavonoids and Total Antioxidant Capacity (TAC) in different samples}

From quantitative analysis it is seen that total phenol content was higher in green form of Amaranthus, seen to be highest in the raw plant (AG1$60.46 \mu \mathrm{g} / \mathrm{ml}$ GAE), followed by the boiled (AG2- $46.5 \mu \mathrm{g} / \mathrm{ml} \mathrm{GAE}$ ) and the fried (AG3-32.99 $\mu \mathrm{g} / \mathrm{ml}$ GAE) samples, whereas the amount of phenol was highest $(39.85 \mu \mathrm{g} / \mathrm{ml} \mathrm{GAE})$ in fried sample (AR3) followed by the boiled sample $(30.013 \mu \mathrm{g} / \mathrm{ml} \mathrm{GAE})$. The total phenolics content was found to be negligible in raw sample of red Amaranthus (AR1) (Table 2). In general flavonoid content was higher in green Amaranthus than the red one. The estimation of flavonoid revealed that fried samples (AV3) of green plant showed highest concentration of total flavonoids (1088.19 $\mu \mathrm{g} / \mathrm{ml}$ QE), followed by boiled (AV2- $932.63 \mu \mathrm{g} / \mathrm{ml} \mathrm{QE}$ ) and the raw (AG1- $914.11 \mu \mathrm{g} / \mathrm{ml} \mathrm{QE}$ ). Among the red Amaranthus, flavonoid content was highest in fried (AR3) and lowest in boiled (AR2) (Table 2). Among green Amaranthus total antioxidant activity was found to be reduced in the fried sample (AG3-20.61 $\mu \mathrm{g} / \mathrm{ml}$ Asc AE which is nearly 10 times lesser than the raw), with highest activity shown in the raw plant material (AG1- $195.61 \mu \mathrm{g} / \mathrm{ml}$ Asc AE) followed by the boiled one (AG2- $169.02 \mu \mathrm{g} / \mathrm{ml}$ Asc AE). Among red Amaranthus, the high content $(264.045 \mu \mathrm{g} / \mathrm{ml} \mathrm{ASC} \mathrm{E})$ of TAC in the fried sample followed by the boiled sample $(86.772 \mu \mathrm{g} / \mathrm{ml} \mathrm{ASC} \mathrm{E})$ and raw sample, indicated that after frying total antioxidant capacity increased in 5 times (Table 2).

Table 2: Estimation of Phenolics, Flavonoids and Total Antioxidant Capacity (TAC) in different samples.

\begin{tabular}{cccc}
\hline Sample & $\begin{array}{c}\text { Total Phenol }(\mu \mathrm{G} / \\
\text { MI Gae })\end{array}$ & $\begin{array}{c}\text { Total Flavonoid } \\
(\mu \mathrm{G} / \mathrm{MI} \mathrm{Qe})\end{array}$ & $\mathrm{Tac}(\mu \mathrm{G} / \mathrm{MI}$ Asce $)$ \\
\hline AG1 & $60.46 \pm 0.285$ & $914.11 \pm 0.77$ & $195.61 \pm 0.032$ \\
AG2 & $46.50 \pm 0.283$ & $932.63 \pm 0.44$ & $169.02 \pm 0.044$ \\
AG3 & $39.99 \pm 0.291$ & $1088.19 \pm 0.2$ & $20.61 \pm 0.12$ \\
AR1 & $0.709 \pm 0.020$ & $543.74 \pm 0.04$ & $49.318 \pm 0.060$ \\
AR2 & $30.013 \pm 0.025$ & $465.93 \pm 0.76$ & $86.772 \pm 0.088$ \\
AR3 & $39.85 \pm 0.035$ & $717.81 \pm 0.044$ & $264.045 \pm 0.036$ \\
\hline
\end{tabular}

All the values of mean $\pm \operatorname{SEM}(n=3)$

\section{Effect of Thermal processing on the antioxidant activity}

Percentage inhibition of DPPH radical, increased in fried and boiled samples, when compared with raw sample. The fried samples had highest free radical scavenging property which were about 25.48\%. in AR3 and $15.71 \%$ in AV3 (Table 3). So it is seen that free radical scavenging activity increased after thermal processing. This holds true for both the boiled and the fried vegetable.

\section{Estimation of Quercetin, Kaempherol and Rutin in each sample}

Results obtained from HPTLC showed that there were no traces of Catechin in all the six samples. In case of green Amaranthus highest Rutin concentration was found to be in the raw sample $(0.62 \mathrm{mg} / \mathrm{g}$ fresh tissue), followed by the fried $(0.48 \mathrm{mg} / \mathrm{g}$ fresh tissue) and boiled $(0.25 \mathrm{mg} / \mathrm{g}$ fresh tissue) samples. Red Amaranthus, was considered, showed highest amount of Rutin, in the raw sample $(1.087 \mathrm{mg} / \mathrm{g}$ fresh tissue), followed by boiled sample. However,complete absence of rutin from the fried sample was quite discomposing. However, among green Amaranthus, highest Quercetin concentration was present in the boiled sample $(0.15$ $\mathrm{mg} / \mathrm{g}$ fresh tissue), followed by the fried $(0.14 \mathrm{mg} / \mathrm{g}$ fresh tissue) and raw $(0.12 \mathrm{mg} / \mathrm{g}$ fresh tissue) samples. Quercetin showed its highest presence $(0.24 \mathrm{mg} / \mathrm{g}$ fresh tissue $)$ in the fried red varieties followed by boiled $(0.02$ $\mathrm{mg} / \mathrm{g}$ ) and a complete absence of it in the raw sample (AR1). Kaempferol was seen only in the raw sample of green Amaranthus $(0.19 \mathrm{mg} / \mathrm{g}$ fresh tissue) (Table 4).

\section{Statistical analysis}

One way ANOVA was done to test the effect of treatments (Green Amaranthus- Phenol, Flavonoid, TAC and antioxidant analysis). $P$-value is $<0.05$, indicating a significant difference between the treatments. Tukey's test was done for pairwise testing, which found the following pairs significant ( $p$-value < 0.05) AG2-AG1, AG3-AG1, AG3-AG2. One way ANOVA was done to test the effect of treatments (Green

Table 3: Effect of Thermal processing on the antioxidant activity.

\begin{tabular}{cc}
\hline Sample & Percentage Inhibition of DPPH Radical \\
\hline AG1 & $9.63 \pm 0.02$ \\
AG2 & $12.01 \pm 0.033$ \\
AG3 & $15.71 \pm 0.067$ \\
AR1 & $9.63 \pm 0.02$ \\
AR2 & $16.01 \pm 0.025$ \\
AR3 & $25.48 \pm 0.025$ \\
\hline
\end{tabular}

All the values of mean $\pm \operatorname{SEM}(n=3)$

Table 4: Estimation of Catechin, Quercetin, Kaempferol and Rutin in each sample.

\begin{tabular}{cccc}
\hline Sample & $\begin{array}{c}\text { Rutin Content } \\
(\mathrm{Mg} / \mathrm{G})\end{array}$ & $\begin{array}{c}\text { Quercetin Content } \\
(\mathrm{Mg} / \mathrm{G})\end{array}$ & $\begin{array}{c}\text { Kaempferol } \\
\text { Content }(\mathrm{Mg} / \mathrm{G})\end{array}$ \\
\hline AG1 & $0.62 \pm 0.03$ & $0.12 \pm 0.31$ & $0.19 \pm 0.28$ \\
$\mathrm{AG} 2$ & $0.25 \pm 0.05$ & $0.15 \pm 0.18$ & Absent \\
AG3 & $0.48 \pm 0.21$ & $0.14 \pm 0.7$ & Absent \\
AR1 & $1.087 \pm 0.03$ & Absent & Absent \\
AR2 & $0.210 \pm 0.13$ & $0.02 \pm 0.25$ & Absent \\
AR3 & Absent & $0.24 \pm 0.08$ & Absent \\
\hline
\end{tabular}

All the values of mean $\pm \operatorname{SEM}(n=3)$ 
Amaranthus- Rutin analysis) where, $P$-value is $<0.05$, indicating a significant difference between the treatments. Tukey's test was done for pairwise testing. The following pairs are significant $(p$-value $<0.05)$ AG2AG1, AG3-AG1, AG3-AG2. One way ANOVA was done to test the effect of treatments (Green Amaranthus- Quercetin analysis). $P$-value is $<0.05$, showing a significant difference between the treatments. Tukey's test was done for pairwise testing. The following pairs are significant ( $p$-value $<0.05)$ AG2-AG1, AG3-AG1. One way ANOVA was done to test the effect of phenol treatment (Red Amaranthus- Phenol analysis). $P$-value is $<0.05$, showing significant difference between the treatments. Tukey's test was done for pairwise testing, showing pairs AR2-AR1, AR3-AR1, AR3-AR2 to be significant ( $p$-value $<0.05$ ). One way ANOVA was done to test the effect of treatment (Red Amaranthus- antioxidant analysis). $P$-value is $<0.05$, therefore showing significant difference between the treatments. Tukey's test was done for pairwise testing. The following pairs are significant ( $p$-value $<0.05)$ AR2-AR1, AR3-AR1, AR3-AR2. One way Anova was done to test the effect of treatment (Red AmaranthusFlavonoid analysis). $P$-value is $<0.05$, therefore there is significant difference between the treatments. Tukey's test was done for pairwise testing. The following pairs are significant $(p$-value $<0.05)$ AR2-AR1, AR3-AR1, AR3-AR2. One way ANOVA was done to test the effect of treatment (Red Amaranthus- TAC analysis). $P$-value is $<0.05$, therefore there is significant difference between the treatments. Tukey's test was done for pairwise testing. The following pairs are significant $(p$-value $<$ 0.05) AR2-AR1, AR3-AR1, AR3-AR2.

\section{DISCUSSION}

Vegetable compositions are usually determined by raw material but for nutritional purposes it should be considered that most of them are cooked before consumption. In India, vegetables are cooked by boiling in water, frying in oil or microwaved. The cooking process alters the physical $^{11,12}$ and chemical composition influencing the concentration and availability of bioactive compounds of vegetables. Both positive and negative effects have been reported depending on the morphological and nutritional characteristics of vegetable species. ${ }^{13-15}$ Complex physical and chemical reactions of phenolic compounds, caused by thermal processing includes leaching of water soluble phenolics, unmasking polyphenols from protein conjugates, degradation of polyphenols, breakdown and transformation of phenolics and formation of Maillard reaction products. ${ }^{16,17}$ Pan frying of vegetables is common in Indian kitchen. The fried material is heated only on the surface so that the phenolic antioxidant losses are insignificant. In case of fried carrot, results indicated a TAC increment, which is probably due to the formation of new antioxidant molecules, such as Maillard reaction products, because oil absorption and its contribution to TAC were both negligible. ${ }^{18}$ From overall experiments of red Amaranthus, the probable explanation to the result is, due to heat (shallow frying), certain protein foldings release the antioxidant properties of the sample, increasing the phenol, flavonoid, quercetin content, compared to raw sample. ${ }^{19}$ Several researchers found similar trends of changes in phenolics upon different types of cooking or heating systems. ${ }^{20}$ Ferracane et al. observed that cooking practices increase the overall caffeoyl-quinic acid concentration due to the formation of different dicaffeoyl-quinic acid isomers. After steaming total phenol content increased $50 \%$, while simmering, frying and blanching reduced the L-ascorbic acid. ${ }^{21,22} \mathrm{DPPH}$ activity increased on thermal treatment in both species due to higher antioxidants, as seen in our result. ${ }^{23}$ Moreover, heat treatment increased free phenolic acids as detected by HPTLC in the sample. However, the paucity of Rutin in fried sample might be due to some protein activities as well. Nevertheless, it could be concluded, this study demonstrated that the oil frying process would be better for enhancing antioxidants and free-radical scavenging potential of the red leafy vegetable.

Our study has shown significant results based on the comparative investigations between fresh and processed leaves of two species of amaranths. In Table 2 we see that in A. tricolor, the phenol content was highest $(39.85 \mu \mathrm{g} / \mathrm{ml} \mathrm{GAE})$ in fried sample followed by boiled sample (30.013 $\mu \mathrm{g} / \mathrm{ml} \mathrm{GAE)} \mathrm{contrary} \mathrm{to} \mathrm{which,} \mathrm{the} \mathrm{phenol} \mathrm{content} \mathrm{was} \mathrm{highest}$ in $A$. viridis, of raw herb $(60.46 \mu \mathrm{g} / \mathrm{ml} \mathrm{GAE})$, followed by the boiled ( 46.5 $\mu \mathrm{g} / \mathrm{ml} \mathrm{GAE})$ and the fried herb $(32.99 \mu \mathrm{g} / \mathrm{ml} \mathrm{GAE})$. Likewise, when flavonoid content was measured, by taking quercetin as the standard, the highest concentration of flavonoid was seen in fried samples of $A$. tricolor (717.81 $\mu \mathrm{g} / \mathrm{ml} \mathrm{QE})$ and A. viridis (1088.19 $\mu \mathrm{g} / \mathrm{ml} \mathrm{QE).} \mathrm{Total} \mathrm{antioxidant}$ capacity (TAC) in A. tricolor show a high content $(264.045 \mu \mathrm{g} / \mathrm{ml}$ ASC E) in fried sample, followed by the boiled sample $(86.772 \mu \mathrm{g} / \mathrm{ml} \mathrm{ASC} \mathrm{E)}$. On the other hand, TAC in fried sample of A. viridis was found to be drastically reduced $(20.61 \mu \mathrm{g} / \mathrm{ml}$ Asc.AE), with highest activity shown in the raw plant material $(195.61 \mu \mathrm{g} / \mathrm{ml}$ Asc.AE) followed by the boiled one $(169.02 \mu \mathrm{g} / \mathrm{ml}$ Asc.AE). Table 3 deals with percentage inhibition of DPPH radical, seen to increase in fried and boiled samples, in both the species of Amaranthus. Results from HPTLC showed the absence of Catechin in the samples. Kaempferol as present only in raw sample of A. viridis (0.19 $\mathrm{mg} / \mathrm{g}$ fresh tissue). Considering other parameters drawn by HPTLC method, presence of rutin and quercetin in both the species could be considered as major underscores. Table 4 documents that, amount of rutin, present in the raw sample of red Amaranthus was highest (1.087 $\mathrm{mg} / \mathrm{g}$ fresh tissue) followed by the boiled sample. However, complete absence of rutin from the fried sample was quite discomposing. Unlike rutin, highest quercetin presence $(0.24 \mathrm{mg} / \mathrm{g}$ fresh tissue) was seen in fried sample of $A$. tricolor followed by boiled $(0.02 \mathrm{mg} / \mathrm{g})$ and complete absence in the raw sample. Highest quercetin in $A$. viridis was present in the boiled $(0.15 \mathrm{mg} / \mathrm{g}$ fresh tissue) plant material, followed by the fried $(0.14 \mathrm{mg} / \mathrm{g}$ fresh tissue) and raw $(0.12 \mathrm{mg} / \mathrm{g}$ fresh tissue) samples.

Hence, the results show that green amaranth in its raw form contains maximum antioxidants, compared to processed samples and fried form of red amaranth is more suitable for uptake. The probable explanation to this result is, in presence of heat (shallow frying), certain protein foldings release the antioxidants of the sample, which fuels the increment of phenol, flavonoid, quercetin content, more than raw sample. However, the paucity of rutin in fried sample was probably due to possible disorientation of antioxidant properties of rutin under heat. This could be cleared further, if, the experiment was being continued longer, by calculating the extractive values and individual content of antioxidant properties per sample.

\section{CONCLUSION}

The plant showed positive results relating its phenol, flavonoid contents; that when consumed, boost the levels of antioxidant. It protects the body from potentially harmful molecules (free radicals), which might cause oxidative stress. The red color of the plant Amaranthus tricolor is due its high content of anthocyanin and it is also a rich source of vitamin C, which acts as an antioxidant in the body. Thus, consuming it as a fried preparation would boost the antioxidant profile in the body, keeping it healthy. Fortunately, eating a diet rich in antioxidants can help neutralize free radicals and reduce the risk of these chronic diseases. Thus, inclusion of Red Amaranthus in daily diet is a necessity. As already mentioned before, our study was almost entirely aimed to draw a comparative notion on the activity of various antioxidants present in Amaranthus viridis based on the effects of thermal processing. We first analyzed a group of common antioxidants (phenolics and flavonoids). Highest phenolic content was noted in the raw sample, highest flavonoid content was found in the fried green Amaranthus. Further, analysis showed that the 
raw vegetable has greater antioxidant capacity and thermal processing decreases it. DPPH assay on the other hand revealed that the free radical scavenging activity increases after thermal processing. Further, with the help of HPTLC, we individually detected and quantified some of the most abundant and well distributed antioxidants which have been reported in many green leafy vegetables, previously. The data revealed that except for Quercetin, the boiled vegetable seems to contain low amount of antioxidants, in general. The content of Quercetin increases after thermal processing. Rutin is most abundant in the plant and is well retained even after thermal treatment. Kaempferol is absolutely susceptible to be lost on heat treatment, which is indicated by the absence of the molecule in both the boiled and fried diet.

All the study indicated that raw form of green and fried form of red Amaranthus are more important in terms of nutritional value.

\section{ACKNOWLEDGEMENT}

We are sincerely thankful to the Head of the Department, Dr. Suchita Sinha for her constant support and to the Principal, Lady Brabourne College for providing the facilities. The authors are thankful to Dr. Alok Hazra, Scientist, IRDM Faculty Centre, Narendrapur, for his useful suggestions and immense support to this work. The authors also like to thank Snigdha Pain, Statistician, Consultant, Sankhya Analytical Research Pvt. Ltd., for statistical analysis.

\section{CONFLICT OF INTEREST}

The authors declare no Conflict of interest.

\section{ABBREVIATIONS}

AG1: Green Amaranthus Raw; AG2: Green Amaranthus Boiled; AG3: Green Amaranthus Fried; AR1: Red Amaranthus Raw; AR2: Red Amaranthus Boiled; AR3: Red Amaranthus Fried.

\section{REFERENCES}

1. Jarapala SR. Nutrition Science in India: Green leafy vegetables: A potent food source to alleviate micronutrient deficiencies. Int Res J Basic Appl Sci. $2017 ; 2(1): 7-13$

2. Moncada S, Higgs A. The L-arginine-nitric oxide pathway. $N$ Engl J Med. 1993;329(27):2002-12.

3. Gerschman K, Gilbert DL, Nye SW, Dwyer FWO. Oxygen poisoning and X irradiation: A mechanism in common. Science. 1954;119:623-6.
4. Ragasa CY, Austria JPM, Sulosa AF, Torres OB, Shen CC. Chemical constituents of Amaranthus viridis. J Agric Food Chem. 1994;51(1):4456-3377.

5. Sivarajan VV, Balachandran I. Ayurvedic Drugs and Their Plant Sources. Delhi: Oxford and IBH Publishing Co. 1994.

6. Roy D, Mallick B, Samanta D. Augmentation of antioxidative potential of in vitro propagated Mentha piperita L. Indian J Exp Biol. 2020;58:131-7.

7. Prieto $\mathrm{R} L, \mathrm{Wu} \times$, Schaich $\mathrm{K}$. Standardized methods for the determination of anti- oxidant capacity and phenolics of foods and dietary supplements. J Agricl Food Chem. 2005;53(10):4290-302.

8. Ozsoy N, Can A, Yanardag R, Akev N. Antioxidant activity of Smilax excelsa L. leaf Extracts. Food Chem. 2008;110(3):571-83.

9. Huang D, Boxin OU, Prior PL. The chemistry behind antioxidant capacity assays $\mathrm{J}$ of Agric Food Chem. 2005;55:1841-56.

10. Gomathi D, Ravikumar G, Kalaiselvi M, Vidya B, Uma C. HPTLC fingerprinting analysis of Evolvulus alsinoides (L.) L. J Acute Med. 2012;2(3):77-82.

11. Rahman K. Studies on free radicals, antioxidants and co-factors. Clinlnverv Aging. 2007;2(2):219-36.

12. Zhang D, Hamauzu Y. Phenolics, ascorbic acid, carotenoids and antioxidant activity of broccoli and their changes during conventional and microwave cooking. Food Chem. 2004;88(4):503-9.

13. Dewanto $\mathrm{V}, \mathrm{Wu} \mathrm{X}$, Adom KK, Liu RH. Thermal processing enhances the nutritional value of tomatoes by increasing total antioxidant activity. J Agric Food Chem. 2002;50(10):3010-4.

14. Ismail $A$, Lee WY. Influence of cooking practice on antioxidant properties and phenolic content of selected vegetables. Asia Pac J Clin Nutr. 2004;13 Suppl:S162.

15. Turkman N, Sari F, Velioglu S. The effect of cooking methods on total phenolics and antioxidant activity of selected green vegetables. Food Chem. 2005;93(4):713-8.

16. Xu B, Chang SKC. Total phenolics, phenolicacids, isoflavones and anthocyanins and antioxidant properties of yellow and black soybeans as affected by therma processing. J Agric Food Chem. 2008;56(16):7165-75.

17. Droge W. Free radicals in the physiological control of cell function. Physiol Rev. 2002;82(1):47-95

18. Miglio C, Chiavaro E, Visconti A, Fogliano V, Pellegrini N. Effects of different cooking methods on nutritional and physicochemical characteristics of selected vegetables. J Agric Food Chem. 2008;56(1):139-47.

19. Kumar BS, Lakshman K, Jayaveera KN, Krishna NV, Manjunath M, Suresh $\mathrm{MV}$, et al. Estimation of Rutin and Quercetin in Amaranthus viridis L. by High Performance Layer Chromatography (HPLC). Asian Journal Exp Sci. 2009;23(1)51-4.

20. Han S, Xu B. Bioactive components of leafy vegetable edible Amaranthus viridis $\mathrm{L}$. as affected by home cooking manners. American J of Food Sci and Techn. 2014;2(4):122-7.

21. Zhu QY, Zhang A, Tsang D, Thang D, Huang Y, Chen ZY. Stability of green tea catechins. J Agric Food Chem. 2005;45(12):4624-8.

22. Jin YS. Antioxidant, Anti-inflammatory and Anti-cancer activities of Amaranthus viridis L. Asian J Chem. 2013;25(16):8901-4.

23. Pramanik P, Ghosh A. Evaluation of Antioxidant Potential of Red and Green Amaranth leaves extracted in different temperature and $\mathrm{pH}$. Annals of Biol Sci. $2014 ; 2(4): 26-32$

Article History: Submission Date : 04-10-2020; Revised Date : 19-12-2020; Acceptance Date : 01-01-2021.

Cite this article: Roy D, Mullick R, Chakraborty N, Ghosh J, Das D, Mallick B. Influence of the Home Cooking Practices on the Bioactive Components of two Important Edible Herbs- Amaranthus viridis and Amaranthus tricolor. Int. J. Pharm. Investigation. 2021;11(1):27-31. 